\title{
PART IV PRACTICAL PROBLEMS OF CHEMOTHERAPY IN LEPROSY
}

IV.1. Clinical and laboratory control in field projects

IV.2. Prevention

IV.3. Combined leprosy and tuberculosis control

IV.4. Practicability

\section{IV.1 Clinical and Laboratory Control in Field Projects}

\section{Dr Browne}

Now on to practical problems of chemotherapy in leprosy. I should like us to discuss first of all clinical and laboratory control in field projects. Many of you are engaged in field projects in leprosy. What is the kind of clinical and laboratory control that you would consider essential in any field project? How often should the doctor go around, how often should smears be taken, how often should biopsies be taken, what kind of control should there be? what are the minimum requirements for an effective leprosy treatment scheme?

\section{Dr Molesworth}

The set up we have in South Malawi covers a million and a quarter people and about $2000 \mathrm{sq}$ miles. We now have 13,000 cases who have passed through our mesh; each one has been charted in detail. Each possibly bacilliferous case has had smears done, and if necessary repeated, and all bacilliferous cases have had repeated smears done. We have had to limit biopsies, simply for the time factor, to aid the diagnosis or to assess progress in research groups. The routine treatment has been carried out faithfully by the staff, not so faithfully by the patients, and as a result we have not been able to increase beyond an average of 50\% regular attenders. The work that was done on our cases showed that nearly all the dapsone that we gave out was consumed by this $50 \%$ of cases. I have always thought that $50 \%$ was too low to achieve control. The lepromatous cases appear rather better at attending, because they see more obvious reason for it than do the non-lepromatous, who may have just an anaesthetic patch with a bit of an edge which does not worry them at all. The results are quite effective in those with a lower BI, they are inevitably slower in those with higher BI.

\section{Dr Browne}

How frequently do you take skin smears?

\section{Dr Molesworth}

In bacilliferous cases one every six months and more frequently in any trial case.

Dr Ellard

In response to the point $\mathrm{Dr}$ Molesworth made about the possibility of malabsorption of dapsone occurring. I should like to say that, as far as I am 
aware, no case has ever been proved of a patient failing to absorb ingested dapsone. There is therefore no reason for trying to estimate dapsone plasma levels when a patient appears not to be progressing as well as he should on dapsone treatment. The essential point is to ensure that the patient is actually swallowing the dapsone tablets he is being given. Ideally every dose should be given under full supervision, but usually this is impracticable. We have recently devised a urine-test method for monitoring the regularity with which leprosy patients take their prescribed dapsone tablets, which can be used to provide evidence as to how serious a problem irregular drug ingestion is. I would entirely agree with Dr Molesworth that there are some patients who won't take their dapsone tablets whatever you do and that in their case it would be best to give dapsone by injection.

\section{Dr Browne}

I have three observations to make. (1) I have seen dapsone tablets in the stools, very hard. (2) Patients in a certain country that shall be nameless, hid dapsone tablets under the tongue despite swallowing a draught of water, they then would spit them out and sell them on the local market. Others would actually swallow the tablet in front of the doctor, and then regorge it. But they got only half the price for such a tablet in the local market because it was bile-stained!

\section{Dr Languillon}

In Senegal we have now an average of 40,000 leprosy patients, among them $8 \%$ lepromatous cases. They are visited once a year, they receive dapsone $600 \mathrm{mg}$ once a week. It is necessary that they take the tablets in front of the nurse because if we don't act like that they frequently don't take the tablets. Once a year we take a nasal smear and a skin smear; no biopsies were taken. The contacts of the lepromatous cases are also visited at the same interval and receive $5 \mathrm{mg} / \mathrm{kg}$ body weight dapsone weekly as prophylaxis after BCG vaccination.

\section{Dr Browne}

Dr Hogerzeil, what are you able to do in the way of a laboratory cover?

\section{Dr Hogerzeil}

We see our patients once every three months, but as some of them have to travel very far, we don't hesitate to send dapsone by post for instance, because we would rather take risks and reach at least $50 \%$ of our patients.

\section{Dr Karat}

In the control programme with which I was associated for several years, 75 to $85 \%$ of patients attended for treatment for more than 42 weeks per year of therapy. We collected 2000 random samples of urine at these clinics and examined them for metabolites of dapsone. To our surprise we found metabolites in $80 \%$. We also conducted a survey of absentees in our programme, and in our experience the absentees were patients with skin lesions either of the indeterminate or tuberculoid variety. There was a small group of patients with severe deformity who had no means of transport. I just wonder how many of the reported 50\% absentees were so deformed that they could not get to the clinic. They also may be patients who feel that their deformities are not being attended to by the control programme. 


\section{Dr Pearson}

In Ethiopia we have two control schemes. One, in the area around Addis Ababa which is sponsored by ALERT, is involved in training, and has considerably more facilities, a larger number of people, a bigger variety of drugs available, and it is easier to get shoes, in other words it is more comprehensive than the leprosy control programme for the rest of Ethiopia, which is very basic, issuing dapsone, but very little else. For what it is worth, the attendance rates in the two control schemes are very close to identical. Under the conditions that we are working in, it looks as if special attention to feet ulcers and so on does not necessarily encourage increased clinic attendance. I was surprised that this does seem to be the case.

\section{Dr Walter}

I think it would perhaps be enough to have smears once a year, provided they are taken properly.

\section{Prof. Pattyn}

What has remained of the study of Lechat made more than 20 years ago? $\mathrm{He}$ found that from a strategical point of view it was sufficient and necessary to make only one smear from one ear lobe for survey purposes.

\section{Dr Browne}

Most of Lechat's records were lost in Iyonda, but we had comparable records in which we compared each of the six cutaneous sites and the two nasal septum sites. We found, that if you have limited time and resources, then two sites, (ear lobe and the edge of an active lesion) will give you the best information of bacillary activity. You don't increase it by adopting Cochrane's method of sixteen smears every three months.

\section{IV.2. Prevention}

\section{Dr Browne}

Are there any practicable methods that we could adopt to prevent leprosy in exposed populations? Where the prevalance rates are higher than $1 / 1000$, everybody must be considered to be exposed. We have thought of acedapsone and BCG, dapsone prophylaxis. Is there a place for, say, one dose of rifampicin for contacts of index cases who were lepromatous upon diagnosis? Are there any other methods that would suggest themselves to you, acedapsone for instance; could we achieve whole population coverage with prophylactic or therapeutic acedapsone?

Prof. Azulay

BCG is known to be a non-specific immunological agent; it should be helpful as a prophylactic measure. My experience with BCG in infants resulted in $97 \%$ of Mitsuda positives; of their mothers, less than $70 \%$ were Mitsuda positive, which seems to me very important. After 12 negative smears, I gave BCG to lepromatous cases. Thirty-five per cent showed a weak lepromin positive reaction. I think that BCG should be considered under immunological aspects. 


\section{Dr Walter}

Concerning the result of chemoprophylaxis that Dr Ramanujam has described, I would like to add that similar results were obtained by Dr Lara in the Philippines in a WHO-assisted study involving about 600 children observed for a periof of five years.

\section{IV.3. Combined Leprosy and Tuberculosis Control}

\section{Dr Browne}

We ought now to spend a few minutes discussing some projects in which two diseases are attacked by the same medical and auxiliary team. The two diseases are both mycobacterial diseases, leprosy and tuberculosis. There are various schemes in operation around the world, and there are suggestions for other schemes in which these two diseases are attacked. I should like some observations on this kind of project, advantages and disadvantages, possible dangers of the polyvalent clinics. Perhaps those of you with some experience would share your views with us.

\section{Dr Ramanujam}

I should like to mention a project in India to assess the value of BCG in prevention of leprosy and to study the inter-relation between tuberculosis and leprosy under surveillance. It has been carried out in cooperation with the Tuberculosis Provincial Trial in the Chingleput district. We thought there should be advantages in combining this BCG provincial trial in leprosy with the tuberculosis provincial trial because much fieldwork will be done with the tuberculosis people and the population will also be ready for examination for the presence of leprosy. Unfortunately the entire population was not surveyed for the presence of leprosy prior to the vaccination procedures, which would have been ideal. Nevertheless the examination of the population is going on and we hope that it will be possible to examine 150,000 at least once in $2 \frac{1}{2}$ years. The future results will show how useful such a joint enterprise will be.

\section{Dr Ellard}

I should like to say something about recent developments in the treatment of tuberculosis that may be relevant to the feasibility of combined treatment schemes for the two diseases. In many rural areas the most satisfactory form of antituberculosis chemotherapy consists of two months initial supervised, and often hospitalized, daily treatment with streptomycin, plus isoniazid plus thiacetazone, followed by 10 months daily self-administered treatment with isoniazid plus thiacetazone. However, although this is a highly effective regimen when given under controlled clinical trial conditions, in practice it is much less successful because of the failure of many patients to collect or take their prescribed treatment regularly. In some urban and semi-urban situations these problems may be overcome by basing treatment on fully supervised twice-weekly doses of streptomycin plus isoniazid, but such a treatment scheme is impracticable in the rural areas where most patients live.

Recent clinical trials have therefore investigated whether effective regimens can be found that can cure tuberculosis within a substantially shorter time and several regimens have now been shown to be highly effective when given for as little as six months. Rifampicin appears to be a vital component of the most effective 
regimens evaluated so far and future studies are likely to be concerned with establishing whether the amount of rifampicin required for effective short-course treatment can be reduced to a level that is financially practical and whether effective short-course regimens can be found requiring less than six months treatment. By contrast all the evidence suggests that with the drugs at present available, the treatment of lepromatous patients must be continued for many years.

\section{Prof. Freerksen}

We have shown that the combined therapy we mainly apply in leprosy is at the same time the most effective treatment against tuberculosis. In some cases where leprosy patients also suffered from tuberculosis-extrapulmonary or pulmonaryboth diseases could be cured without any additional treatment. Meanwhile numerous cases of pure tuberculosis are successfully treated. In paucibacilliferous cases treatment with Isoprodian is sufficient. It is as effective as the therapy $\mathrm{RAMP}+\mathrm{INH}+\mathrm{EMB}$ in tuberculosis.

I believe that it would be too early to conceive a general programme for all of us today. But it is necessary to examine systematically whether leprosy treatment and tuberculosis treatment-or rather the control of these two diseases-could be approached as one single task.

\section{Dr Molesworth}

We have exactly such a pilot project starting in Malawi in a central area where we presume that there is a $15 / 1000$ prevalence of leprosy, which is probably at least that of tuberculosis. Hitherto all tuberculosis treatment has been confined to the clinics. The idea is to combine in our mobile units the double function of leprosy control and treatment with tuberculosis treatment and control. The diagnosis of leprosy often takes a long time, sometimes it is easy and quick but with our system of charting, it takes a certain amount of time. The diagnosis of tuberculosis on the other hand should be reduced to the positive sputum, and those are the cases we treat. If we are certain that the person has tuberculosis, in spite of two negative sputa, then he will be referred to the district hospital where an X-ray examination and further laboratory facilities are available. Whether the programme will work or not depends on the dedication of the teams concerned. In fact they will have to work out a modus operandi of the timing factor, because otherwise the tuberculosis worker is going to finish his treatment and his case finding quickly, whereas the leprosy doctor is still looking for small macules. Alternatively the leprosy worker has finished and the tuberculosis worker is still wandering around.

What will happen I just don't know, but I believe firmly that this project is feasible and practicable.

\section{Dr Browne}

I have heard the objection that patients with lepromatous leprosy would stand a higher risk of contracting pulmonary tuberculosis if they are exposed in the same clinic week by week to those suffering from open tuberculosis.

\section{Dr Molesworth}

This is true. 


\section{IV.4. Practicability}

\section{Dr Browne}

The last point to discuss is the practicability of the treatment we advise; injections or oral treatment, daily, weekly, monthly, three monthly treatment; how to encourage regularity and perseverance and how to do all this on 40 pence per head per year for all medical services, including leprosy.

\section{Dr Hogerzeil}

There is indeed a very small budget per head of population in developing countries, but the patients are much more willing to contribute than we are inclined to believe. In the area where I am working about $25 \%$ of our budget comes from the patients themselves without any reservation at all. It is one of the things I am always happy to show to our visitors because if you look at our outpatient department you will find very many beggars from the streets of Hyderabad and Bombay who appear to have nothing to give, but they produce a certain amount which will cover their treatment for a whole year. It is a kind of a medical insurance, including if necessary orthopaedic reconstruction of their hands, being operated on by a highly skilled surgeon from Vellore or elsewhere. It doesn't make any difference whether they get tuberculosis, for they are then treated in hospital for three months daily with streptomycin, all this is included and they know it. This comes as a great surprise to many people who treat leprosy in India. As far as I know we have the highest income of all leprosy hospitals in India from our patients, without any pressure at all, because never has any patient been refused treatment on economic grounds or inability to offer payment. Twenty per cent of our patients don't pay anything at all and they get exactly the same care and attention as others. The second point I would like to mention is that while such projects as we have discussed here aim at the highest standards, I couldn't help thinking about the contrast which we have to contend with in rural areas, often a hundred miles away from the nearest centre. A scientist or a research worker hates making a compromise; I would say that the field worker's life is just one continued compromise. It would be lovely if from this meeting some practical suggestions came about regarding the acceptibility of compromise. For instance, when we were working in Nigeria, if I am right, we had a certain meaning about a relapse rate of $6 \%$ of our patients over a considerably long period.

I quite agree that it is good for a lepromatous patient to get life-long treatment, but how can we do so in India with $\frac{3}{4}$ million patients in our state. One demoralizes the patient by saying that he has to go on taking drugs for life. What about our borderline cases? Do we really have to keep them on for five or seven years? I am very happy indeed with what Dr Pearson has said, to have courage and send the patient away if you know that you cannot have a reasonable amount of supervision. On the other hand it is wonderful to hear about the treatment with rifampicin. But the suggestion of giving only one high dose treatment was really not done on scientific grounds, but only prompted by the fact that unless we manage to do something important for the patients in one single blow (which is $1500 \mathrm{mg}$ in our case), we won't be able to do anything at all. We can't even give a patient four capsules daily for a week. That would come to 210 rupees, and it will constitute more than a month's wages.

When we come for instance to the treatment of reactions, many people have 
said with justifiable pride "We never had to resort to corticosteroids among our reaction patients", but I would plead for the compromise of giving corticosteroids. I have considerable experience with corticosteroids as a dermatologist. We must not say that all corticosteroids in reactions are taboo, because the patients are going to become steroid-dependent. From this viewpoint we always have to make compromises in the duration of treatment, compromises in the way of giving corticosteroids, risking perhaps in one of a hundred a dependence, compromise in the choice of drug and so on.

\section{Dr Pearson}

One of the things that might help in reducing the costs of a leprosy control programme is in reducing the costs of maintaining staff. The costs of the drugs, of the ordinary ones, don't really come into it. I think it is possible that by lengthening the period between visits of staff, the costs of running a programme could be considerably reduced. This would have to be balanced-you have to see a patient a certain number of times to establish the necessary relationship with him so that he continues treatment and so on. In my experience, a surprising number of patients in Malaya who lived many miles away, several hundred miles, became used to being given one year's supply of dapsone at a time. They came up for their annual visits regularly within a few days, and this was over five or six years. Maybe our patients are different, more sophisticated, but I think this is something that would be worth serious consideration in reducing the costs, or making money available for other things.

\section{Dr Browne}

When surveying leprosy in the mountainous valleys of Nepal I met a man who walked for 41 days to get treatment, over mountains up to $12,500 \mathrm{ft}$ high. We cannot possible think of that man coming every week for his treatment. Another little comment comes from French West Africa where "auto-traitement", self-treatment, is a most practical proposition in places where roads are non-existent for nine months in a year, where the population is sparsely scattered and where the medical occupation is so embryonic that one doctor can pay a visit only once a year during the dry season when there are roads, to patients who need his help. By enlisting the aid of literate village chiefs it is possible to conduct a leprosy control service even in such a situation. The literate chief has a supply of dapsone tablets and a list of patients who need treatment. When they have run out of tablets, they walk to him, perhaps for several days, and get their drugs. The number of tablets is inscribed in an almost illiterate hand in the register. This may be the only possibility of getting leprosy and tuberculosis treatment to the villagers who need it. It is a far cry from the sophisticated developed clinics of Addis Ababa or Sungei Buloh or Chingleput, but it is the only practicable proposition for millions of our fellow citizens in this world.

In conclusion, I should like to thank all who have participated in the discussions and in the most helpful listening, as all those who have come to the front will doubtless agree. I now adjourn this Colloquium, and know I express the feelings of us all when I offer our most grateful thanks to Professor Freerksen, to Dr Thumim, and also to our able translators, unseen, but not unheard, who have helped us tremendously, and to everyone else concerned. Thank you very much. 